\title{
Resolving of optimal fractional PID controller for DC motor drive based on anti-windup by invasive weed optimization technique
}

\author{
Badriyah Ahmed Obaid ${ }^{1}$, Ameer Lateef Saleh ${ }^{2}$, Abbas Kareem Kadhim ${ }^{3}$ \\ ${ }^{1}$ Department of Electrical Engineering, Southern Technical University, Iraq \\ ${ }^{2}$ Department of Electrical Engineering, University of Misan, Iraq \\ ${ }^{3}$ Department of Electrical Power Engineering Techniques, Iraq
}

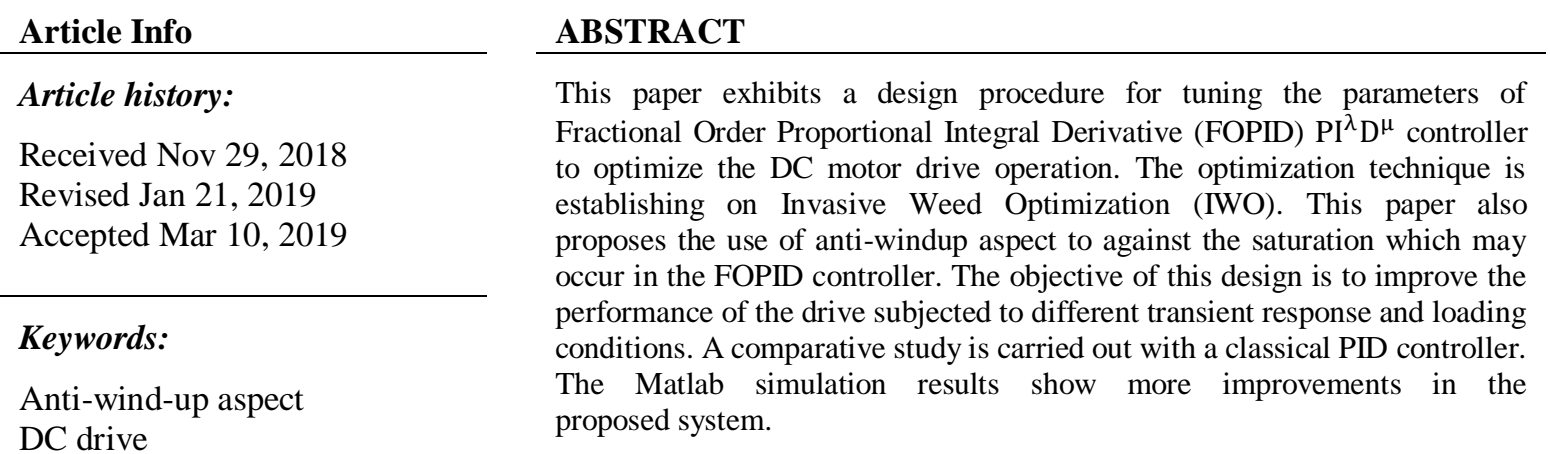

FOPID controller

Invasive weed optimization technique

\section{Corresponding Author:}

Abbas Kareem Kadhim,

Department of Electrical Power Engineering Techniques,

Middle Technical University,

Baghdad, Iraq.

Email: alzubaidy_abbas@yahoo.com

\section{INTRODUCTION}

Fast response, robotic, reliable and wide speed range are the primary demands for industrial drive applications. One of the most used drives is the DC motor drive due to its easy and flexible controllability with high initial torque. The development in control devises to ensure effective efficiency in such system and making them intelligent is so important aspect [1-2]. The most extensive DC motor drive control is the PID control. Beside the trail and error method, different classical tuning PID parameters are used, such as ZieglerNichols (Z-N), internal control methods [3-5] etc. A new extension for PID controller is its fractional order PID. It provides more degree of freedom due to the order of differentiation $(\mu)$ and the order of integration $(\lambda)$. Where the most controlling strategy is the applied source voltage controlled by using the DC-DC converter [6] used to control the motor speed directly.

The use of FOPID controller with DC drive provides extra advantages in freedom performance such as rising time, settling time, phase margin [7], etc. To optimize the parameters of PID and FOPID controller, there are several methods utilized. Some of these methods are intelligent such as Genetic Algorithm (GE) [5], Particle Swarm Optimization (PSO) [3-4], Ant and Bee colony [8-9], etc. Invasive Weed Optimization (IWO) technique is utilized for tuning PID controller parameters in drives other than DC drive such as in brushless DC motor drive [10].

When saturation in PID output is occurred due to transient or load change conditions, the control system will be out of control. This case is called the windup phenomenon [11]. Therefore, the anti-windup 
process is necessary. The PID controller based on the anti-windup strategy is applied to control the speed of brushless DC motor drive [11]. This paper combines between FOPID and anti-windup for DC motor drive and IWO for designing and tuning all the related parameters. Matlab Simulink is used to verify the drive performance using the proposed controller over the using of classical PID controller.

\section{THE DC MOTOR MODEL}

The Electric motors are widely utilized in a variety of commercial, residential, and industrial processes. As the reference the shunt-type DC motor connection is shown in Figure 1, a shunt-coil DC motor consists of a shunt wound connected with the armature in parallel. Therefore, these types of motors have an excellent position and speed control. Hence DC shunt motors are typically utilized in many applications that demand a more precise speed control system.

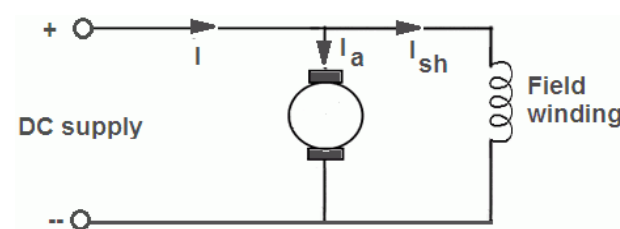

(a) Circuit diagram of shunt DC motor.

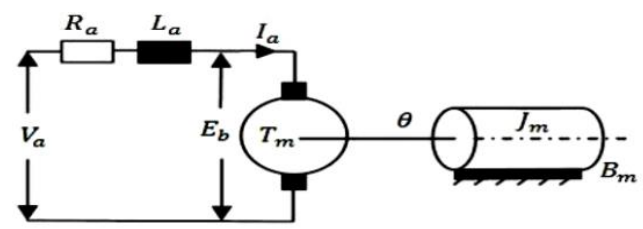

(b) Schematic diagram of DC motor

Figure 1. Shunt-type DC motor

The mathematical models of the electrical and mechanical equations of the shunt DC motor are given by the following (3), (4), (7). The armature voltage equation of the motor can be written as:

$$
v_{a}(t)=R_{a} i_{a}(t)+L \frac{d i_{a}(t)}{d t}+e_{b}(t)
$$

The back emf equation of the motor can be given as:

$$
\mathrm{e}_{\mathrm{b}}(\mathrm{t})=\mathrm{k}_{\mathrm{b}} \omega(\mathrm{t})
$$

Now the torque equation can be expressed as:

$$
\mathrm{T}_{\mathrm{m}}(\mathrm{t})=\mathrm{k}_{\mathrm{t}} \mathrm{i}_{\mathrm{a}}(\mathrm{t})
$$

The equation of mechanical part is represented as:

$$
\mathrm{T}_{\mathrm{m}}(\mathrm{t})-\mathrm{T}_{\mathrm{L}}=\mathrm{j} \frac{\mathrm{d} \omega(\mathrm{t})}{\mathrm{dt}}+\beta \omega(t)
$$

where $\mathrm{k}_{\mathrm{t}}$ is the torque constant, $\mathrm{k}_{\mathrm{b}}$ back emf constant, $\mathrm{T}_{\mathrm{m}}(\mathrm{t})$ motor torque, $\mathrm{T}_{\mathrm{L}}$ is the load torque; $\mathrm{j}$ is the rotor inertia; $\beta$ is the friction constant.

After combine the upper equations together:

$$
\begin{aligned}
& \mathrm{v}_{\mathrm{a}}(\mathrm{t})=\mathrm{R}_{\mathrm{a}} \mathrm{i}_{\mathrm{a}}(\mathrm{t})+\mathrm{L} \frac{\mathrm{di}_{\mathrm{a}}(\mathrm{t})}{\mathrm{dt}}+\mathrm{k}_{\mathrm{b}} \omega(\mathrm{t}) \\
& \mathrm{k}_{\mathrm{t}} \mathrm{i}_{\mathrm{a}}(\mathrm{t})=\mathrm{j} \frac{\mathrm{d} \omega(\mathrm{t})}{\mathrm{dt}}+\beta \omega(\mathrm{t})
\end{aligned}
$$

\section{CONTROL DESIGN}

\subsection{Fractional Order $\operatorname{PID}\left(\mathrm{PI}^{\lambda} \mathrm{D}^{\mu}\right)$ Controller}

$\mathrm{PI}^{\lambda} \mathrm{D}^{\mu}$ controller is derived from a conventional PID controller established upon fractional order differentiation and integration. The $\mathrm{PI}^{\lambda} \mathrm{D}^{\mu}$ controller has five control parameters $\left(\mathrm{K}_{\mathrm{p}}, \mathrm{Ki}, \mathrm{K}, \lambda\right.$, and $\left.\mu\right)$ that requirement tuning to get a robust controller with extra freedom and provide better control of dynamic systems [9, 12, 13]. 
The $\mathrm{P} \mathrm{I}^{\lambda} \mathrm{D}^{\mu}$ controller can be describing as:

$$
u(t)=K_{p} e(t)+K_{i} D^{-\lambda} e(t)+K_{d} D^{\mu} e(t)
$$

where $e(t)$ : the error between the actual output and a desired set point; $u(t)$ : the control output. The transfer function of this controller can be expressed as follow:

$$
\mathrm{G}(\mathrm{s})=\mathrm{K}_{\mathrm{p}}+\mathrm{K}_{\mathrm{i}} \mathrm{S}^{-\lambda}+\mathrm{K}_{\mathrm{d}} \mathrm{S}^{\mu}
$$

The orders of integration and differentiation are respectively $\lambda$ and $\mu$ may be positive real number or integers. By taking $\lambda=1, \mu=1$ can be obtained conventional PID. Moreover can produce conventional PI \& PD controllers by taking $\lambda=1, \mu=0$ and $\lambda=0, \mu=1$ respectively. The block diagram of $\mathrm{PI}^{\lambda} \mathrm{D}^{\mu}$ controller is shown in Figure 2.

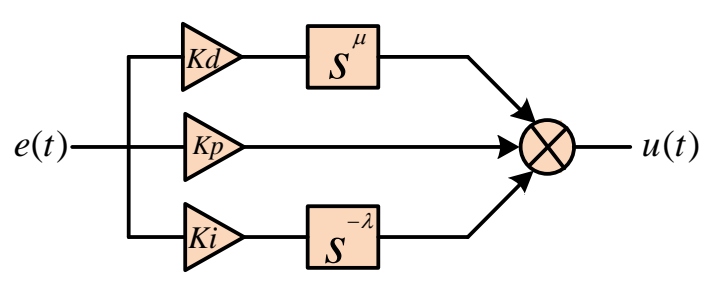

Figure 2. Block diagram of FOPID controller

\subsubsection{Anti-windup technique}

The windup phenomenon is occurred due to the saturation in the output of the PID controller, which causes the integrator windup and thus the controller's performance will be decreased. The saturation occurred if the controller contains integral action, the error will continuous and integrated to become too big and influential. At the control signal reaches the minimum or maximum limit of the actuator, then control of saturation will happen. This episode makes the feedback-loop inexact because the actuator stays on its minimum or maximum limit independently of the operation output $[11,14]$.

To overcome this windup phenomenon, anti-windup techniques have been utilized to minimize performance retreating and may be classified into three categories: tracking back calculation, conditional integration and limited integrator schemes [14].

In this paper, a tracking back-calculation method is utilized to overcome the windup phenomenon. The basic idea in a method of back calculation, when saturates the controller output, the integral term is begun to recomputed so that its new value after resetting gives an output at the saturation limit. By this way, the difference between the saturated control signal and unsaturated control signal is utilized to produce a feedback signal with tracking time constant $T_{t}$. The input signal to integral term is $[14,15]$ :

$$
\mathrm{e}_{\mathrm{i}}=\mathrm{k}_{\mathrm{i}} \mathrm{e}+\frac{1}{\mathrm{~T}_{\mathrm{t}}}\left(\mathrm{u}-\mathrm{u}^{\prime}\right)
$$

Where e is the error of the system; $u$ and $u$ ' are the saturated and unsaturated control output signal; $T_{t}$ is the tracking time constant which can determine the speed resetting of the integral.

\subsubsection{The Proposed Controller of Combine $P I^{\lambda} D^{\mu}$ Controllers with Anti-Windup Technique}

The $\mathrm{PI}^{\lambda} \mathrm{D}^{\mu}$ Controllers with Anti-windup technique has been proposed to speed control of DC motor. In this paper, the proposed controlled include $\mathrm{PI}^{\lambda} \mathrm{D}^{\mu}$ controller which utilized to improve the accuracy of the output system with good performance and more flexible; the anti-windup back-calculation method is utilized to overcome the saturation in the output controller signal. Where tracking back calculation is based on recalculating the fractional integral term during linear and saturation range by using limiter such as $[16,17]$ :

$$
e_{i}=\left\{\begin{array}{c}
e k_{i} \text { if } u=u^{\prime} \\
e k_{i}+\frac{1}{T_{t}}\left(u-u^{\prime}\right) \text { if } u \neq u^{\prime}
\end{array}\right.
$$


Where the differential equation of the $\mathrm{PI}^{\lambda} \mathrm{D}^{\mu}$ is modified with anti-windup technique to produce the equation of the proposed $\mathrm{PI}^{\lambda} \mathrm{D}^{\mu}$ based on an anti-windup controller as [18]:

$$
u(t)=K_{p} e(t)+K_{i} I^{-\lambda} e_{i}(t)+K_{d} D^{\mu} e(t)
$$

where the parameters of the proposed system are tuning and optimized using IWO algorithm to give better control for speed response. The generalized block diagram of the $\mathrm{PI}^{\lambda} \mathrm{D}^{\mu}$ controller with anti-windup techniques is shown in Figure 3.

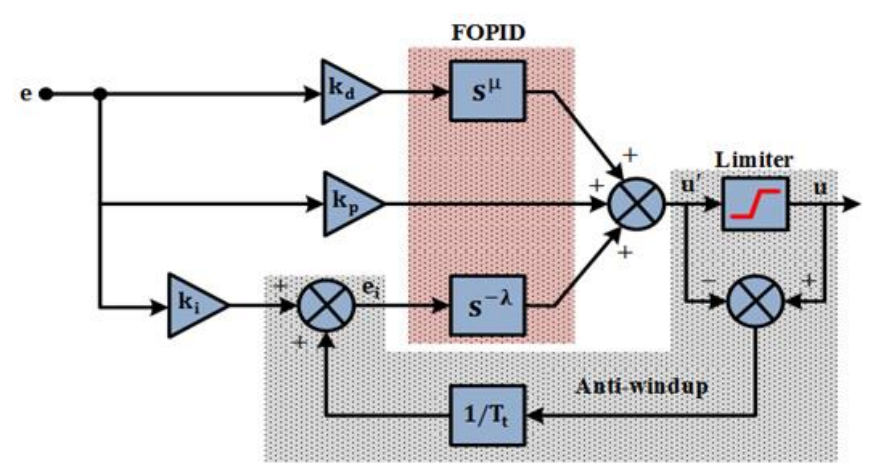

Figure 3. Block diagram of the $\mathrm{PI}^{\lambda} \mathrm{D}^{\mu}$ with anti-windup techniques

\subsubsection{Invasive Weed Optimization Technique}

The Invasive Weed Optimization (IWO) algorithm was presented firstly 2006 by Mehrabian and Lucas [19]. It is easy and simple to program and understands and also has robustness and rapid global searching ability. Over the specified area the seeds finite number are being spread, any seed produce a new weed and then the weed will produce other weeds from its seeds based on its fitness. The computational experiments show that the IWO is a highly competitive property where it is able to find the best and optimal solutions for the instances studied [20,21].

The unwanted growing plants are called weeds, which have adaptive and robust nature. That will turn them into unfavorable plants in agriculture. A common agronomy belief is that "The Weeds Always Win". The motivated new algorithm is colonization of invasive weeds by a common agriculture phenomenon. Figure 4 shows the algorithm flow chart. The specifics of the IWO are classified as follows:

A. Commence: Weeds are generated randomly over the search space as the inhabitance of initial solution.

B. Estimation: Calculate the fitness of each weed in the inhabitance of the controller parameters.

C. Propagation: The best weed's fitness in the population will produce more seeds while the worst weed's fitness will produce fewer seeds depending on the response of the DC motor variables [21, 22]. The increase of seeds number produced is linear based on weeds' fitness depending on the following formula:

$$
\text { weed }_{\text {num }}=\mathrm{S}_{\min }+\left(\mathrm{S}_{\max }-\mathrm{S}_{\min }\right) \frac{\mathrm{f}-\mathrm{f}_{\text {worst }}}{\mathrm{f}_{\text {best }}-\mathrm{f}_{\text {worst }}}
$$

where weed $_{\text {num }}$ is a number of weeds, $S_{\text {max }}, S_{\text {min }}$ are maximum and minimum seeds respectively, $f$ is the current fitness of the weed and $\mathrm{f}_{\text {best }}, \mathrm{f}_{\text {worst }}$ are the best and the worst current inhabitance fitness.

D. Spatial Dispersal: Here weed will generate seeds around it leading to each plant local search. According to a normal distribution with variance $\sigma^{2}$ and mean equal to zero, the producer of the parent weed surrounded by randomly spread seeds to generate new controller gains. However, the random function standard deviation $\sigma$ will be reduced from an already defined elementary value $\sigma_{\text {initial }}$ to a final value $\sigma_{\text {final }}$ in each generation As a function of iteration (iter.) as:

$$
\sigma_{\text {cur }}=\sigma_{\text {final }}+\left(\sigma_{\text {initial }}-\sigma_{\text {final }}\right) \frac{\left(\text { iter }_{\max }-\text { iter }\right)^{\mathrm{n}}}{\left(\text { iter }_{\max }\right)^{\mathrm{n}}}
$$


where $\sigma_{\text {cur }}$ is the current standard deviation, iter ${ }_{\max }$ is the maximum number of iteration and $\mathrm{n}$ is the nonlinear modulation index. So that, $\sigma$ determine weeds exploration ability. Therefore, the search capacity of all weeds is progressively reduced as iteration increases. At the end of the optimization operation, the search capacity has decreased so much that each weed can only find its position with respect to the smallest DC motor speed error.

E. Competitive Alienation: Through increasing of the iterations, the number of weeds in the colony will reach its maximum, and adopted the removal mechanism. The parents and their seeds are associated together and only those with the best fitness of the DC motor output can stay life and become genital others are being removed.

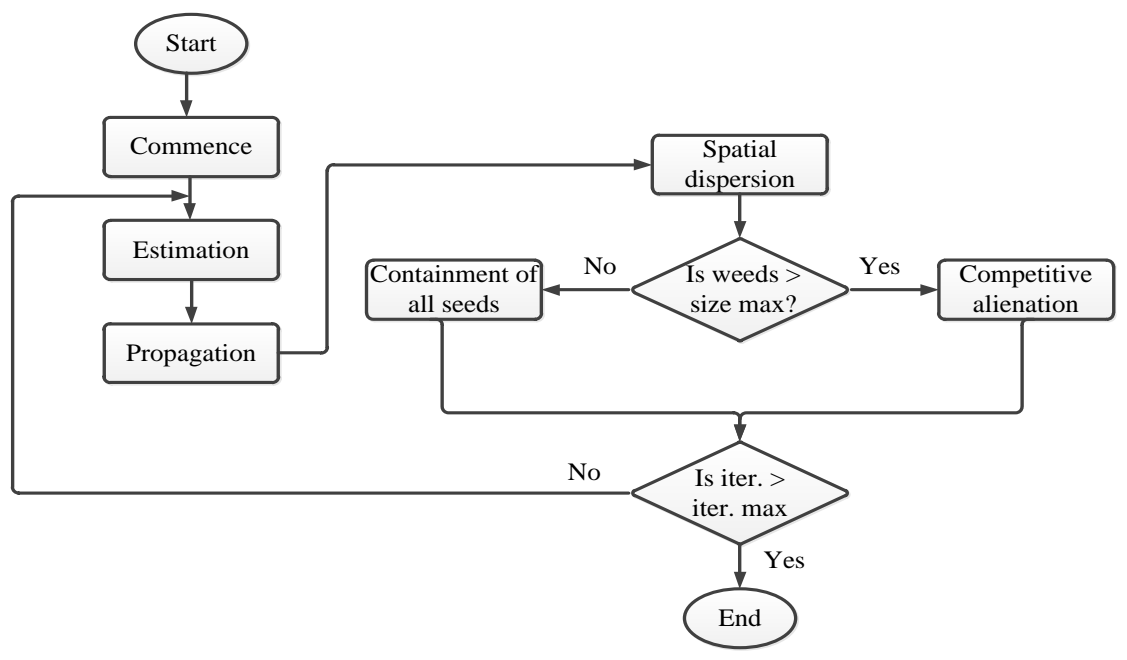

Figure 4. IWO flow chart

\section{SPEED CONTROL OF DC MOTOR DRIVE SYSTEM}

The $\mathrm{PI}^{\lambda} \mathrm{D}^{\mu}$ Controllers with Anti-windup technique based on invasive weed algorithm has been proposed to control the speed of shunt DC motor. Figure 5 shows the overall block diagram of the speed control drive system with the IWO algorithm for tuning the parameters of the proposed controller. Where the drive system consists of a shunt DC motor, DC-DC converter, and proposed controller with the IWO algorithm. The speed of shunt DC motor is directly proportional to its input voltage. The input voltage has been controlled utilizing a DC-DC converter connected to the input of the DC motor. The proposed controller is utilized to control the duty cycle of the DC-DC converter using PWM technique according to the speed error. The PWM signal is supplied to the DC-DC converter to get the required amplitude voltage to preserve the desired speed. Table 1 shows the values for the parameters of the DC motor.

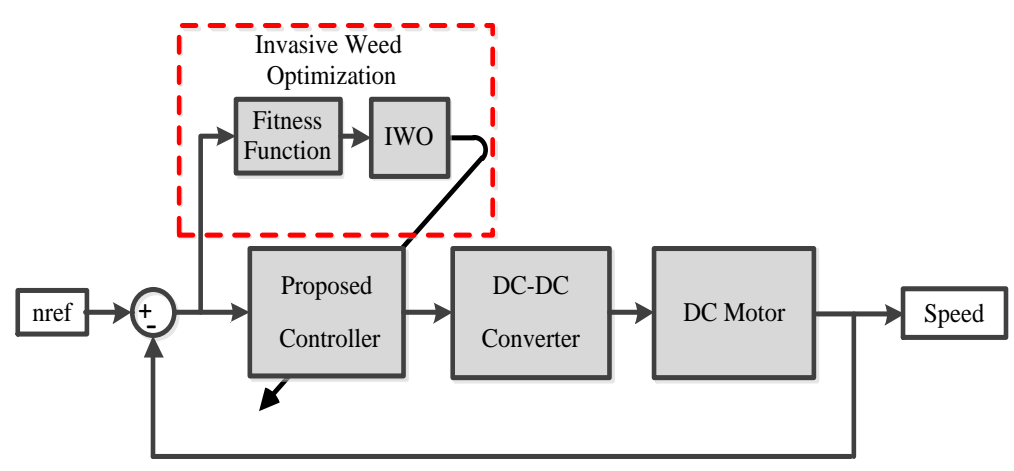

Figure 5. Block diagram of DC motor drive system 
The Simulink model of shunt DC motor has been constructed based on the mathematical model in (1-6) is shown in Figure 6. In this system, one closed loop utilized to control the speed where the actual speed is compared with the desired speed to get it the error signal which is provided to the proposed controller that had built according to (7-11) as shown in Figure 7.

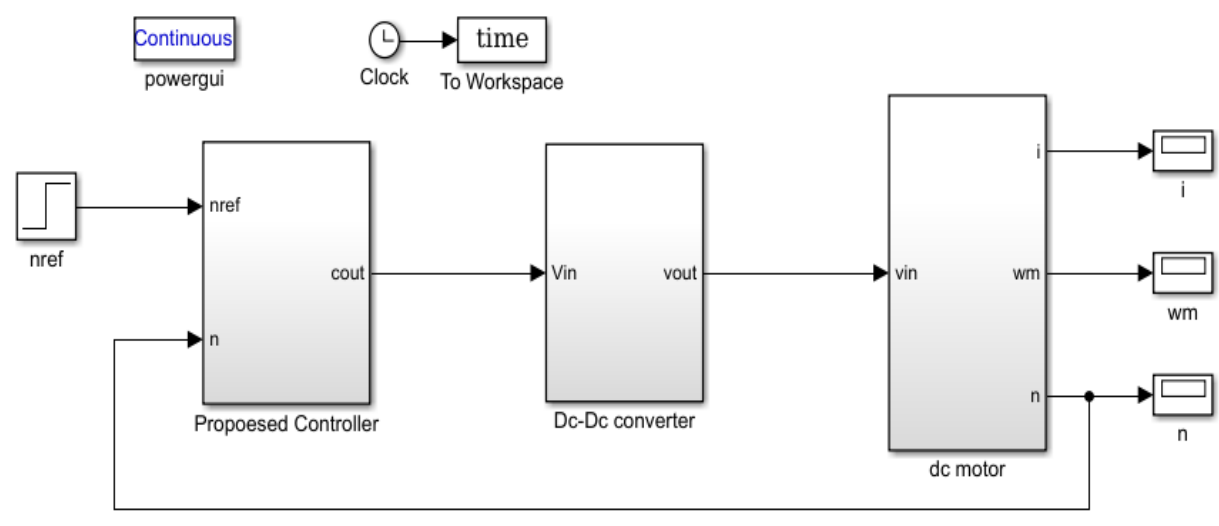

Figure 6. Simulink model of DC motor with optimal FOPID controller and Anti-windup technique

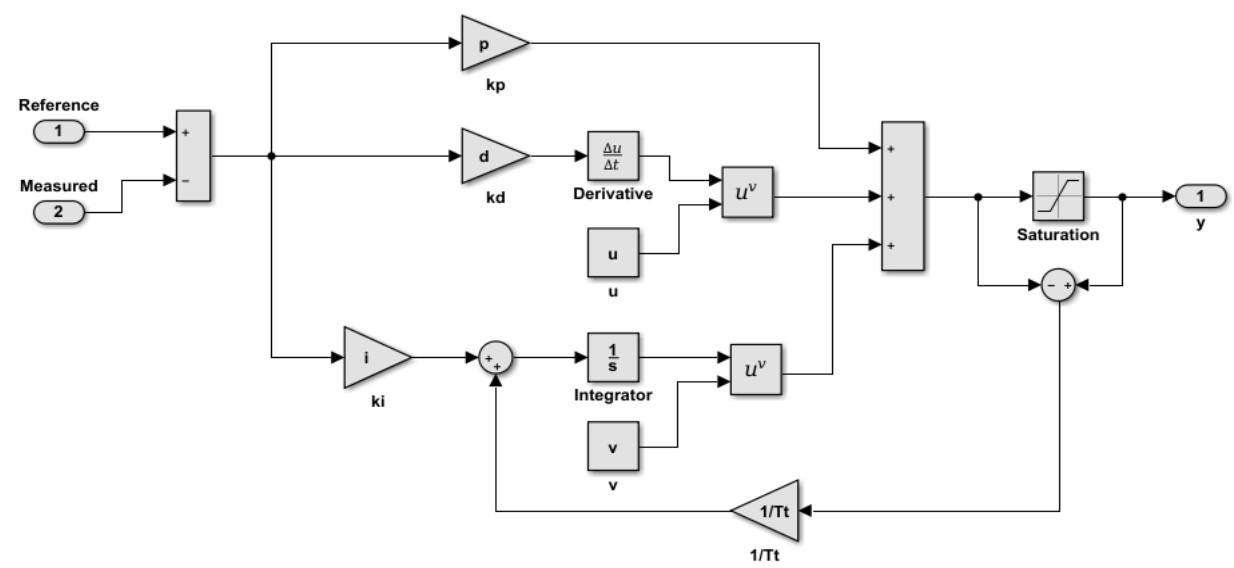

Figure 7. Simulink model of FOPID controller based on anti-windup technique

Table 1. DC Motor Parameters

\begin{tabular}{lcc}
\hline Motor Parameter & Value & Unit \\
\hline Armature inductance $(\mathrm{L})$ & 0.5 & $\mathrm{H}$ \\
Armature resistance $(\mathrm{R})$ & 1 & $\Omega$ \\
Mechanical inertia $(\mathrm{J})$ & 0.01 & $\mathrm{Kg} \cdot \mathrm{m}^{\wedge} 2$ \\
Friction coefficient $(\mathrm{B})$ & 0.1 & $\mathrm{~N}-\mathrm{m} / \mathrm{rad} / \mathrm{sec}$ \\
Back emf constant $\left(\mathrm{k}_{\mathrm{b}}\right)$ & 0.01 & $\mathrm{~V} / \mathrm{rad} / \mathrm{sec}$ \\
torque constant $\left(\mathrm{k}_{\mathrm{t}}\right)$ & 0.01 & $\mathrm{~N} \cdot \mathrm{m} / \mathrm{A}$ \\
Armature voltage $(\mathrm{V})$ & 220 & $\mathrm{~V}$ \\
Rated speed & 1500 & $\mathrm{rpm}$ \\
\hline
\end{tabular}

\section{SIMULATION AND RESULTS}

The complete model of shunt DC motor with optimal FOPID controller and anti-windup technique is implemented in Simulink/Matlab program version (2017a). The validity of the proposed controller to control the speed of shunt DC motor has been achieved by implement several tests under different operating conditions such as speed response during no load and a sudden step change in load at reference speed. The parameters of those controllers are achieved by running the IWO algorithm online with its variables which are shown in Table 2. After that, the proposed controller parameters are obtained as shown in Table 3. 
The cost function used by IWO to optimize the parameters of the proposed controller as:

$$
\mathrm{F}=\min \left(\int \mathrm{e}_{\mathrm{s}}^{2} \mathrm{dt}+\mathrm{Mp}\right)
$$

where $\mathrm{F}$ is the fitness function, es is the speed error, and $\mathrm{Mp}$ is the maximum overshoot.

Table 2. IWO Parameters

\begin{tabular}{lc}
\hline \multicolumn{1}{c}{ Parameter type } & Value \\
\hline Number of initial plants & 5 \\
Maximum number of plants & 100 \\
Maximum iteration number & 50 \\
Maximum seeds number & 5 \\
Minimum seeds number & 1 \\
Initial standard deviation & 10 \\
Final standard deviation & 0.0000001 \\
Modulation index & 3 \\
Dimension & 6 \\
\hline
\end{tabular}

Table 3. Proposed Controller Optimized Parameters

\begin{tabular}{lc}
\hline Parameters & Values \\
\hline Proportional $\mathrm{k}_{\mathrm{p}}$ & 15.67 \\
Differential $\mathrm{k}_{\mathrm{d}}$ & 0.03291 \\
Integral $\mathrm{k}_{\mathrm{i}}$ & -4.955 \\
Order of differentiation $(\mu)$ & 1.177 \\
Order of integration $(\lambda)$. & 0.8887 \\
Tracking time constant $\mathrm{T}_{\mathrm{t}}$ & 2.848 \\
\hline
\end{tabular}

Figures 8 and 9 shows the comparison between the conventional and proposed PID controllers for the speed and current curves responses at the reference speed $1200(\mathrm{rpm})$ with no load condition, and a sudden load of $1 \mathrm{Nm}$ is added at $\mathrm{t}=0.5 \mathrm{sec}$.

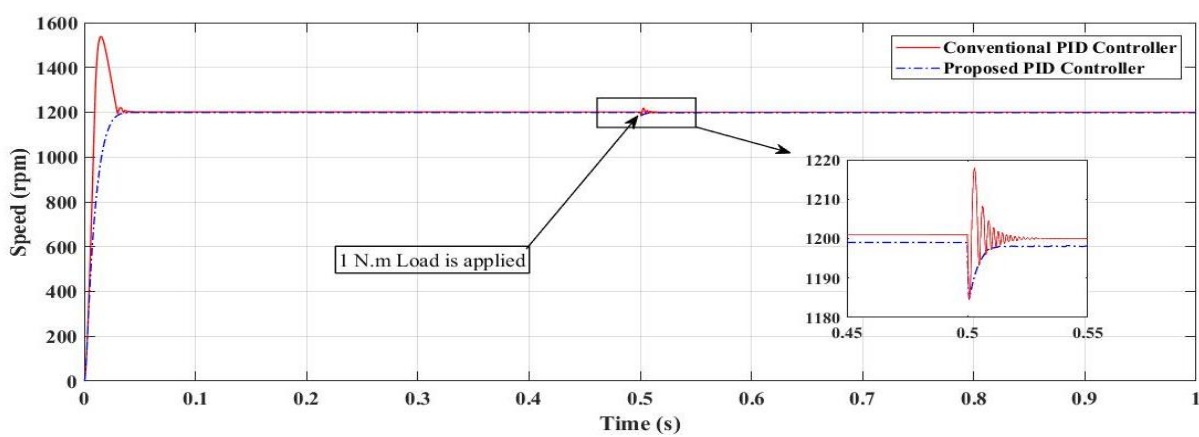

Figure 8. Comparison of the speed responses between the conventional and proposed PID controllers

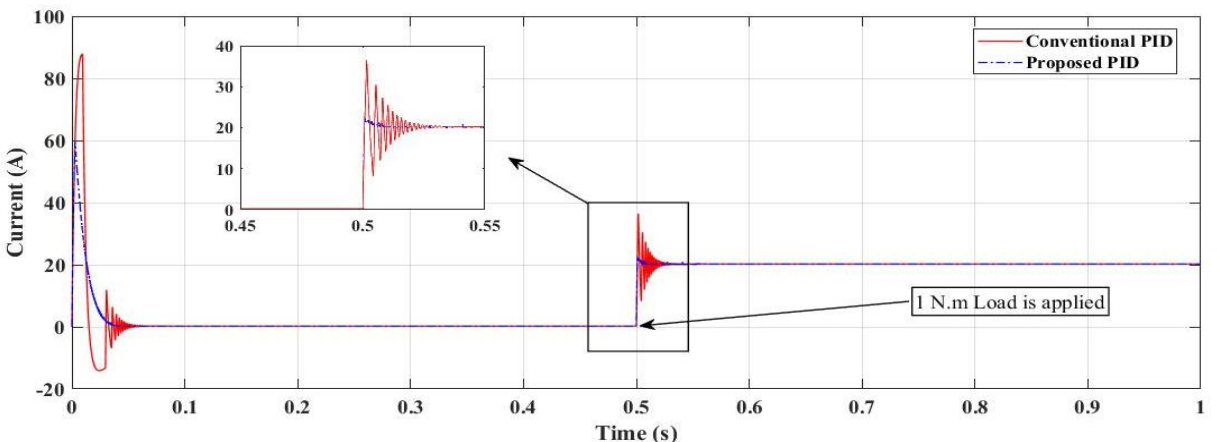

Figure 9. Comparison of the current responses between the conventional and proposed PID controllers 
While the step change in the speed is shown in Figure 10. Where the motor is started by $500 \mathrm{rpm}$ then after $0.2 \mathrm{~s}$ increased to $1200 \mathrm{rpm}$ then after $0.4 \mathrm{~s}$ reduced to $800 \mathrm{rpm}$ and finally at $0.6 \mathrm{~s}$ changed to $1500 \mathrm{rpm}$. While the step change in the torque load at reference speed $1200 \mathrm{rpm}$, where the load is being changed from no load at starting and a sudden load of $0.5 \mathrm{~N} . \mathrm{m}$ is added at $0.2 \mathrm{~s}$ and increased to $1 \mathrm{~N} . \mathrm{m}$ at 0.4 and reduced to $0 \mathrm{~N} . \mathrm{m}$ at $0.6 \mathrm{~s}$ and finally increased to $1 \mathrm{~N} . \mathrm{m}$ at $0.8 \mathrm{~s}$. Those load step changed are appearing at the responses of speed and current as shown in Figures 11.

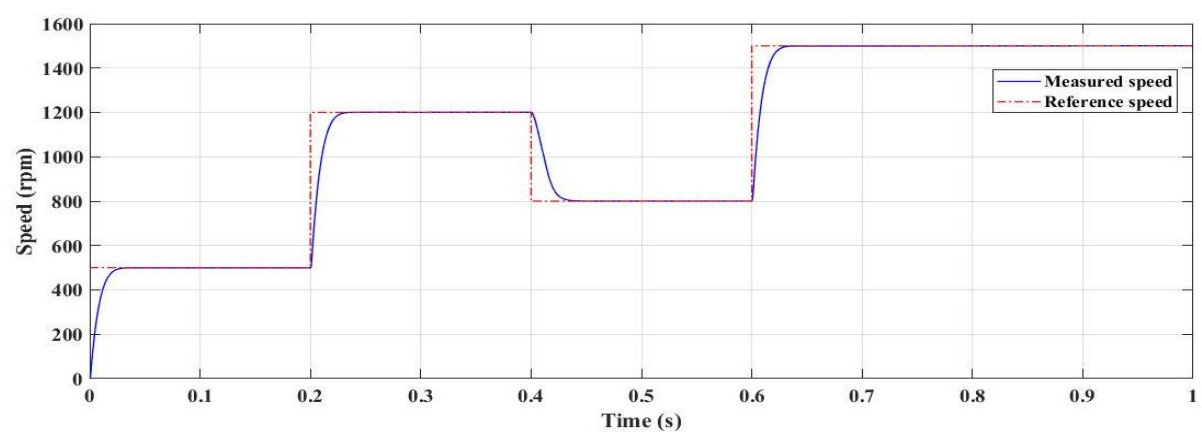

Figure 10. Speed response to the step change reference speed

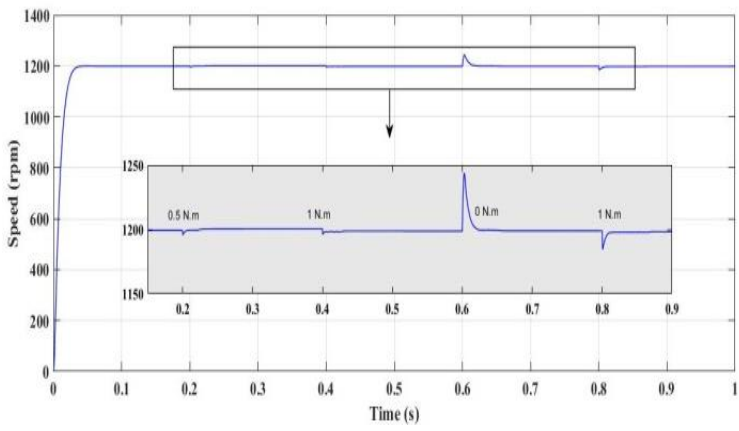

(a)

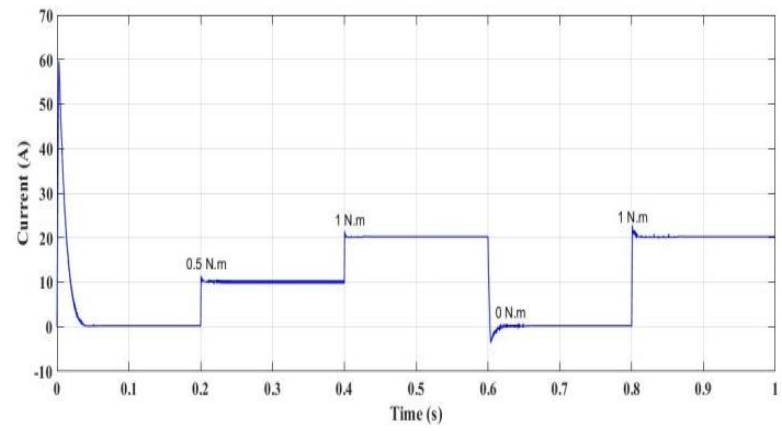

(b)

Figure 11. (a) Speed response to the step change load torque, (b) Current response to the step change load torque

From the above results, it can be noticed that the proposed controller is better as shown in its speed and current responses from where getting rid of the ripple and more flexibility for saddening changing of the speed and applied torque with saving the stability of the desired speed.

\section{CONCLUSION}

This paper present $\mathrm{PI}^{\lambda} \mathrm{D}^{\mu}$ Controllers with Anti-windup technique based on the IWO algorithm to control the speed of DC motor. The IWO technique is applied for learning the parameters of the proposed controller. The simulation results show that this controller improves speed response under all conditions and provides robust stability compare with the conventional PID controller, where the speed control of shunt DC motor becomes softer. From the emulation results, it has found that the proposed PID controller improved the overshoot and steady state error furthermore it provides softly and strong steadiness as liken to the same traditional PID controller.

\section{REFERENCES}

[1] B. Singh, S. Prakash, A. Pandey and S. K. Sinha, "Intelligent PI Controller for Speed Control of DC Motor," Int. Journal of Electronic Engineering Research, vol.2, no.1 pp. 87-100, 2010.

[2] P. Tripuraa,Y. Srinivasa and K. Babub, "Intelligent Speed Control of DC Motor using ANFIS," Journal of Intelligent \& Fuzzy Systems, vol. 26, pp. 223-227, 2014. 
[3] W. Elsrogy, M. Fkirin and M. Moustafa Hassan, "Speed Control of DC Motor using PID Controller Based on Artificial Intelligence Techniques," IEEE Int. Conf. on Control Decision and Information Technologies (CoDIT) (Tunisia), pp. 196-201, 2013.

[4] S. Suman and V. Giri March, "Speed Control of DC Motor using Optimization Techniques Based PID Controller," 2nd IEEE Int. Conf. on Engineering and Technology (ICETECH) (Coimbatore, India), pp. 581-587, 2016.

[5] A. Rincon, F. Angulo and F. Hoyos, "Controlling a DC Motor through Lypaunov-like Functions and SAB Technique," International Journal of Electrical and Computer Engineering (IJECE), vol. 8, no. 4, pp. $2180-2198,2018$.

[6] Premalatha R. and P. Murugesan, "Comparison of Filter with Fuzzy Controlled Three Levels DC-DC Converter Fed Drive," Int. Journal of Engineering Research in Africa, Trans Tech Publications, vol. 14 pp. 63-74, 2015.

[7] A. Roy and S. Srivastava, "Design of Optimal PI $\lambda \delta \delta$ Controller for Speed Control of DC Motor Using Constrained Particle Swarm Optimization," IEEE 2016 Int. Conf. on Circuit, Power and Computing Technologies (India), pp. 1-6, 2016.

[8] A. Mishra, A. Khanna, N. Singh and V. Mishra, "Speed Control of DC Motor Using Artificial Bee Colony Optimization Technique," Universal Journal of Electrical and Electronic Engineering, vol.1 no.3 pp. 68-75, 2013.

[9] T. Amieur, M. Sedraoui and O. Amieur, "Design of Robust Fractional-Order PID Controller for DC Motor Using the Adjustable Performance Weights in theWeighted-Mixed Sensitivity Problem," International Journal of Robotics and Automation (IJRA), vol. 7, no. 2, pp. 108-118, 2018.

[10] A. Obed and A. Kadhim, "Multi-Resolution Wavelet PID Speed and Current Controllers of BLDC Motor Based on Invasive Weed Optimization Technique," International Journal of Applied Engineering Research ISSN 0973-4562, vol. 13, no. 8 pp. 6234-6243, 2018.

[11] A. Kadhim and A. Obed, "Brushless DC Motor Speed Control Based on PID Controller with 2-DOF and AntiWindup Techniques," 2nd Engineering Conference for Graduate Research Middle Technical University-Electrical Engineering Technical College (Baghdad Iraq), pp 1-14, 2017.

[12] A. Saleh and A. Obed, "Speed Control of Brushless DC Motor Based on Fractional Order PID Controller," Int. Journal of Computer Applications, vol. 95, no.4, June 2014.

[13] A. Saleh, M. Hussain and S. Klim, "Optimal Trajectory Tracking Control for a Wheeled Mobile Robot Using Fractional Order PID Controller," Journal of University of Babylon Engineering Sciences (Iraq), vol. 26, no.4, pp. 292-306, 2018.

[14] S. Sung, J. Lee and I. Lee "Process identification and PID control," (John Wiley \& Sons).

[15] H. Shin and J. Park, "Anti-Windup PID Controller with Integral State Predictor for Variable-Speed Motor Drives," IEEE Transactions on Industrial Electronics, vol.59, no.3, pp. 1509-1516, 2012.

[16] S. Pandey, P. Dwivedi and A. Junghare, "A Newborn Anti-Windup Scheme Based on State Prediction of Fractional Integrator for Variable Speed Motor," IEEE 17th Int. Conf. on Control, Automation and Systems (Ramada Plaza Jeju Korea), pp. 663-668, 2017.

[17] F. Padula, A. Visioli and M. Pagnoni, "On the Anti-Windup Schemes for Fractional-Order PID Controllers," IEEE Int. Conf.on Power Electronics, Intelligent Control and Energy Systems (Delhi India) pp. 1-4, 2012.

[18] S. Pandey, P. Dwivedi and A. Junghare, "Anti-Windup Fractional Order PI $\lambda$-PD $\mu$ Controller Design for Unstable Process: a Magnetic Levitation Study Case Under Actuator Saturation," Springer Arabian Journal for Science and Engineering vol. 42, no. 12, pp. 5015-5029, 2017.

[19] A. Mehrabian and C. Lucas, "A Novel Numerical Optimization Algorithm Inspired from Weed Colonization," Ecological informatics, vol.1, no.4, pp. 355-366, 2006.

[20] S. Mekni and B. Fayech, "A Modified Invasive Weed Optimization Algorithm for Multi-Objective Flexible Job Shop Scheduling Problems," Computer Science \& Information Technology, pp. 51-60, 2014.

[21] M. Khalilpour, N. Razmjooy, H. Hosseini and P. Moallem, "Optimal Control of DC Motor Using Invasive Weed Optimization (IWO) Algorithm," Majlesi Int. Conf. on Electrical Engineering (Iran), January 2011.

[22] B. Nayak and S. Sahu, "Parameter Estimation of DC Motor through Whale Optimization Algorithm," International Journal of Power Electronics and Drive System (IJPEDS), vol. 10, no. 1, pp. 83-92, 2019. 